\title{
FIX, Andrew C., KARANT-NUNN, Susan C., Germania Illustrata. Essays on Early Modern Germany Presented to Gerald Strauss
}

\section{Olivier Christin}

\section{(2) OpenEdition \\ Journals}

Édition électronique

URL : http://journals.openedition.org/ifha/1989

DOI : $10.4000 /$ ifha. 1989

ISSN : 2198-8943

Éditeur

IFRA - Institut franco-allemand (sciences historiques et sociales)

Référence électronique

Olivier Christin, «FIX, Andrew C., KARANT-NUNN, Susan C., Germania Illustrata. Essays on Early Modern Germany Presented to Gerald Strauss », Revue de I'IFHA [En ligne], Date de recension, mis en ligne le 01 janvier 1994, consulté le 22 septembre 2020. URL : http://journals.openedition.org/ifha/1989; DOI : https://doi.org/10.4000/ifha.1989

Ce document a été généré automatiquement le 22 septembre 2020.

(C)IFHA 


\title{
FIX, Andrew C., KARANT-NUNN, Susan C., Germania Illustrata. Essays on Early Modern Germany Presented to Gerald Strauss
}

\author{
Olivier Christin
}

1 Une fois encore, il faut saluer le travail éditorial accompli par les éditeurs du Sixteenth Century Journal de Kirksville (Missouri) dont la collection d'essais et d'études est en train de devenir une référence. Ce volume en apporte une nouvelle illustration pour tous ceux qui s'intéressent à l'histoire de l'Allemagne moderne. Cette Festschrift offerte à Gerald Strauss (auteur notamment de Sixteenth Century Germany: Its Topography and Topographers, 1959; Historian in an Age of Crisis: The Life and Work of Johannes Aventinus, 1963; Nuremberg in Sixteenth Century, 1966; et du controversé Luther's House of Learning, 1978) rassemble treize contributions de quelques-uns des meilleurs spécialistes de l'Allemage moderne (A.C. FIX et S.C. KARANT-NUNN, mais aussi H.J. HILLERBRAND, H.A. OBERMAN, M. USHER CHRISTMAN, M.U. EDWARDS, H. SCHILLING, H.-CHR. RUBLACK, R. PO-CHIA HSIA, M.E. WIESNER, TH.A. BRADY, H.C.E. MIDELFORT et R.L. GAWTHROP), précédées d'un survol de l'œuvre de Gerald Strauss.

2 L'ensemble est certes un peu disparate - c'est le sort de toute Festschrift - et les trois parties (vie intellectuelle, société, politique) paraissent plutôt artificielles, mais les contributions sont de grande qualité. On remarquera celle de H.A. OBERMAN (p.19-34), qui montre avec force comment le progrès des études juives à la fin du Moyen Age et au début du XVIe s. n'a pas affaibli, mais transformé et peut-être renforcé l'antisémitisme. Dans une autre optique, R. PO-CHIA HSIA (p.169-180) évoque lui aussi le sort des minorités - Juifs, Tsiganes, mais également les Catholiques des régions protestantes, les Calvinistes ... - dans le "puzzle confessionnel« (p.175) qu'est devenu l'Empire aux XVIeXVIIe s. La question des minorités se retrouve enfin dans le texte de H. SCHILLING (p. 99-120), qui décrit la pluralité religieuse des débuts de la Réforme (avant 1525-1530) dans l'Allemagne de l'Ouest et du Nord (villes de la Baltique, Schleswig-Holstein, Frise, 
Westphalie, Hesse) et l'existence d'alternatives nombreuses (Anabaptistes, Spiritualistes, Zwingliens ...) à la Réforme luthérienne. H.S. recherche les conditions qui assurèrent le triomphe final $\mathrm{du}$ modèle luthérien, reprenant au passage quelques problématiques désormais connues: la Réforme des villes du Nord comme Gemeindereformation, la culture civique des élites urbaines comme facteur propice au modèle luthérien, la confessionalisation.

3 Toutes les contributions mériteraient d'être résumées brièvement, mais on se contentera ici d'en évoquer encore trois pour leur originalité ou pour leur importance. Avec une grande finesse et des sources de première main très consistantes, H.-CHR. RUBLACK examine l'écart entre les attentes religieuses, intellectuelles et éthiques du clergé luthérien et les pratiques effectives des fidèles. Cette distance culturelle, cette incompréhension mutuelle et irritée, nourrit une forme d'anticléricalisme. M.U. EDWARDS révèle l'importance de l'imprimerie strasbourgeoise dans la diffusion de la pensée de Luther et ce dès 1519-1520. Il analyse également la réception des écrits du réformateur, en s'appuyant notamment sur les publications strasbourgeoises de Ulrich von Hutten, Laux Gemigger et Lazarus Spengler. Dans une contribution plus polémique et volontairement paradoxale, TH. BRADY s'interroge sur les particularités de l'Empire et sur sa longévité et conclut que ce n'est qu'après 1800 qu'»une nouvelle histoire a commencé, un Sonderweg par lequel l'Allemagne ne s'éloignait pas de l'Ouest, mais s'en rapprochait« (p.216).

Olivier CHRISTIN 